\title{
Hospital Foundation: A SWOT Analysis
}

\author{
Guilhermina Rego, Rui Nunes
}

Faculty of Medicine, University of Porto, Porto, Portugal.

Email: ruinunes@med.up.pt

Received February $16^{\text {th }}, 2010$; revised May $22^{\text {nd }}, 2010$; accepted July $22^{\text {nd }}, 2010$.

\begin{abstract}
The reform of Portuguese public hospitals can be described as an evolution by "waves". A first "wave" took place in 2002, when 34 public hospitals were transformed into State-owned hospital enterprises (SA hospitals). Subsequently, in January 2006, the SA hospitals and some of the traditional public administration hospitals (SPA hospitals) were changed into public business enterprises (EPE hospitals). That was the second "wave" that is the stage we are at present. A possible third "wave" can be related with the possibility of conversion of the EPE hospitals into State Hospital Foundations $(\mathrm{SHF})$. This paper tries to identify if this new management model has more capacity to influence positively values such as efficiency, equity, quality, governance, empowerment and accountability than the previous existing model. For this purpose it was developed a strategic analysis including an evaluation of some internationals experiences, and also a SWOT analysis was performed. The authors conclude that the introduction of SHF model is a very plausible alternative. The model of governance can make the difference and promote its implementation. Due to the participative management model, the process of accountability can be more "visible" and the regulatory process of this management model seems to be more effective.
\end{abstract}

Keywords: Corporatisation, Hospital Foundation, New Public Management, SWOT Analysis, Portugal, United Kingdom

\section{Introduction}

Throughout these last decades there have been profound changes in the role of Public Administration in the health sector. According to Majone, we are experiencing a paradigm change between the positive state - intervenetionist - and the regulatory state [1,2].The traditional functions involving production and distribution of goods and services have been progressively substituted by functions in the area of financing, services and regulation. Even though, presently, there is a clear separation of these functions to avoid any incompatibility and there is a tendency to reinforce the regulatory role of the state. According to Rosanvallon [3], this evolution involves reinforcement in the competencies of local administration - with the decentralization of the competencies, with non public organisations taking on the public services and the de-bureaucratization and rationalization of the management of the main public services. The health sector is a good example of this reformation process.

The lack of efficiency in the public sector is due, as George Boyne suggests, to the monopolist essence of the market structure of this sector, to the lack of valid indicators of organisational performance and over-sizing of some of the public operators [4]. In these last decades, the introduction of market system and, therefore, the subsequent corporatisation in the public sector, is foreseen as a tool to control public expenditure and balanced budget in many western countries. The development of this new management direction was partly due to the burden of social expenditure based on the Welfare State model and, consequently, the excess of public expenditure and public debt. On the other hand, an increase in the citizens' expectations regarding their rights to quality public services and the incapacity to meet the population needs, as a result of the complexity of the administrative machine, was observed [5].

This alternative is based on the proposition that the legitimacy of the public sector activities should be evaluated according to the outputs, the outcomes and the efficiency [6]. Another perspective of coordination and control of activities developed by public organisations is at issue [7]. The aim is to have a management model focussed on results and centred on performance and efficiency. The bet on quality, consequence of the market system, is an essential feature especially in the health sector. Furthermore, the introduction of this model reflects the difficulties in governing without the active in- 
volvement of the citizens. The term empowerment expresses this concept and reflects the social need for a proactive participation of the citizens in the complex decisions that affect the community [8].

In this perspective it seems legitimate to foster the implementation of management models of the public services that integrate the citizen, the community, internal and external clients, and the different stakeholders as formal members, institutionally recognised by the governance model of public institutions rendering services of public and social interest [9]. This means that a constant adaptation of the public administration to the citizens' expectations is necessary [10] and the health system should adapt to this perspective (responsiveness).

In Portugal the increase of the total health expenditure in particular the public expenditure [11] determined a restructure of the NHS. As a result, different mixes for the public-private management, financing and ownership of hospitals were created. The reform of public hospital management can be described as an evolution by "waves". A first "wave" took place in 2002, when 31 public hospitals were transformed into State-owned hospital enterprises (SA hospitals). Subsequently, in January 2006, the SA hospitals and some of the traditional public administration hospitals (SPA hospitals) were changed into public business enterprises (EPE hospitals). That was the second "wave" that is the stage we are at present.

In this context and taking into account the international reform scenario in the health sector, the aim of this study is to analyse the possibility of adoption of State Hospital Foundation as an evolution of corporatisation of public hospitals. And subsequently to evaluate the impact of this management model which implies a new type of ethical and social governance in healthcare.

\section{Materials and Methods}

Considering the current state of the health sector, an analysis of the institutional statute of public hospitals will be carried out to develop a new hospital management model. This evolution necessarily implies a change in the organisational culture of all the agents in the process - not only the shareholder but all the stakeholders [12]. As a result of arguments concerning the poor quality of healthcare, the state's financing incapacity, the professionalisation of the public and private sectors, amongst others, many studies were developed to analyse possible solutions. The common goal was to establish a comparison between different hospital management models and analyse which one seems to be, considering the social, cultural, economic and political reality of the country at issue, the most appropriate in view of the most modern theories of corporate governance [13]. Emphasis was given to the fact that besides the agency theory and the transaction costs economics theory, another important economic theory underlying the concept of corporate governance is the stakeholders theory that conveys the key idea that different stakeholders, both internal and external to the organisation, are affected by its performance $[14,15]$.

In this context, we intend to analyse a possible third "wave" of hospital reforms in Portugal having as background evidence from the United Kingdom, namely the possibility of conversion of the EPE hospitals (second wave reform) into State Hospital Foundations. This analysis tries to identify if this type of hospital management tends to be globally better than the previous existing model (EPE hospitals). For this purpose a strategic analysis is performed and afterwards a SWOT analysis is developed to evaluate this new model.

The traditional model of Public Administration which gave origin to the National Health Service at the United Kingdom, Portugal and other industrialised countries had positive aspects for society. However, we are presently experiencing some inadequacies resulting from an evolution of the societies which not only question some of the traditional principles but also invoke certain systemic and structural problems [16].

In Portugal, the traditional public hospital with financial and administrative autonomy, even though endowed with some functional independence (SPA hospital), in effect until 2002, revealed a considerably limited autonomy, due to its significant dependence on the Ministry of Health in matters regarding finance, management and recruitment of human resources. Criticism to this type of model refers to a deficient management, which is reflected in the low productivity and lack of quality, a general deresponsibilitization on the part of the management board, the non-existence of an incentive system, which can in some way lead to lack of motivation and professsional performance, and the increase in expenditure due to inefficient management of the resources available.

Portugal, as other European countries, promoted new hospitals management models. The Private Finance Initiative (PFI) was also experimented, a form of hospital privatisation [17] used since 1992 in the United Kingdom or in Spain. However, the real structural health reform in Portugal began in 2002, when the legislation concerning the corporatisation of the state-owned hospitals (SA hospitals) was approved. In a first wave the SA hospital was set up [18]. The aim was to use it to professionalise and expedite management and, consequently, obtain better results in terms of efficiency, effectiveness and equity. Improvement in efficiency and effectiveness in hospital management presupposes the adoption of policies, such as providing the human resources with management tools; promoting the information systems; expediting the deci- 
sion processes by creating responsibility and expenditure centres; improving flexibility in the negotiating capacity; adapting an incentive system according to objectives; and implementing evaluation models according to competencies that are projected not only as tools for resource optimization but also as a means for promoting social equity.

Its implementation implied the adoption of a new financing, contracting, as well as a new management model. It was considered the regime of individual work contract and financing through payment of the acts and activities effectively performed.

In 2005, a second wave of reforms in which 31 SA hospitals (first wave) were changed into EPE hospitals was accomplished. The main alterations introduced with the transformation of SA hospitals into EPE hospitals, imply a greater intervention from the state though maintaining the logic of corporatisation. It was essentially a change in the institutional format due more to political constraints than motives of an organisational nature.

However, since the state's economic and financial unsustainability is still a reality, to rethink the governance model of the hospitals is instrumental to meet the population's expectations adequately. In this manner, and considering that the right to health protection is a social right of the citizens [19], the central objective of this study is to analyse to what extent the State Hospital Foundation provides a better application of the principles of corporate governance [20] and of regulatory governance [21], promoting in this manner improvement in efficiency and equity. And, in this context, be regarded as an evolution in hospital corporatisation.

The implementation of this new model implies a new institutional statute. It is a state entity intended to be used to improve public service management and increase the state's capacity to meet its needs in primarily social areas. It arises from the vital need to provide the state with the capacity to respond to the real needs and expectations of the population with more efficiency and responsiveness. In view of this, it is intended with this new institutional statute to modernise the existing management model, by resorting to legal instruments that will allow more management autonomy, and thus increase the capacity in the areas of finance management, human resources, supplies, as well as in certain investments and others, consequently promoting more quality. Even though still highly regulated and controlled by the state [22].

This management autonomy is reflected in the need to professionalise management and develop a new incentive structure that will in turn be reflected in the relation that will exist between the state and the hospital, both through the management contract [23] and the development of new accountability mechanisms [24]. This model is pe- culiar with regards to decentralization, empowerment and, consequently, with a formal sharing in the management and decision-making processes of the stakeholders, internal and external to the institution. Thus, it is expected that this management model will constitute a more prompt, transparent and participative alternative, and therefore more accountable to society. It is intended to obtain significant improvement in the organisational performance, in particular in the quality, focus on patient/client, efficiency and innovation components.

In effect, the innovation of this model has to do with the management and decision-making process. Whereas, in the EPE hospitals this process results exclusively from a public, state process, in the Hospital Foundations management is not merely public and of the state as it results from the intervention and participation of the civil society, accounting to the public supervising body by means of a goal and result system [25].

The foundational model seems, in this manner, to adapt more adequately to the present and future profile of the health institutions that, in spite of their public nature, appear to be more and more competitive and, therefore, will tend to focus on achieving added value, concentrate on the different stakeholders, emphasize result optimization and performance evaluation, as well as value innovation and entrepreneurism. Furthermore, attributes such as greater autonomy, a matrix and participative structure, a high degree of flexibility and openness, localization and local, national and global coverage, integrated in an interdependent network strengthens this governance model.

This governance model can, however, be refined through the accounts of some international experiments that have some empirical evidence already available. Moreover, with the description of these experiments it is intended to analyse with more detail and depth its potentialities and its weaknesses. For this purpose, and as an example, we have resorted to the experience of the British Foundation Trust. This option is mainly due to the closeness in the underlying principles of the Portuguese and British National Health Service.

In the United Kingdom, the National Health Service (NHS), established in 1948, is divided into several "Strategic Health Authorities", which are responsible for the local management of the NHS, constituting various types of Trusts that are responsible for managing the multiple NHS services of the geographical area. They are entrusted with the "ownership" of the health management at local level to guarantee a more efficient system. One of the organisms included in these Trusts is the Foundation Trust. This new model was instituted in 2003 and its introduction was authorized for the first time in 2004. Up to 1 June 2009, in England, there are 121 NHS Founda- 
tion Trusts. In particular, in their current form they do not include many measures of the outcomes of healthcare treatment (for example, whether there are variations between trusts in the quality of treatment or care for specific conditions).

This management model was instituted with the objective of providing health services to the citizens respecting, however, the underlying principles of the NHS (free assistance, based on need and not capacity to pay) as well as being subject to norms, performance ratings and supervision systems. This is a new hospital model, directed by managers and local staff as well as members of the public, which adapts more easily to the needs of the local population since it has management and financial autonomy. Thus one of the strengths of this model is associated with the transfer of ownership and responsibility to the local community, enabling the NHS Foundation Trusts to adjust its services to the needs and expectations of the local population, in a more effective, efficient and just manner.

In this framework the Hospital Foundation aims, on the one hand to decentralize the public services, delegateing power and responsibility at local level, providing a more adequate response to the local population. It is expected that this type of institution will not only promote a more just access to the health services, but also provide the population with more quality services. On the other hand, this model equally intends to restore accountability duties to local stakeholders, including the patients and NHS staff. This objective derives from the governance model developed by the NHS Foundation Trusts operate governance arrangements that give local stakeholders and the public opportunities to influence the overall stewardship of the organisation and its strategic development. NHS Foundation Trusts. The model grants the stakeholders the possibility to influence the global management of the organisation and its strategic development.

This is because they run according to a democratic model in which the local population and the staff elect directly their representatives for the Board of Governors who, together with the Board of Directors - responsible for the current management of the Foundation, guarantees that the NHS Foundation Trust performs within the limits of its work licence, assisting in defining the organisation's strategic direction, oriented by the needs of the community. Thus, it is their duty to collaborate with the local community and to encourage the population to take active part in this process to guarantee that there is a balanced representation of the different stakeholders.

Similarly to the other NHS organisations, the Foundation Trusts, as they are part of the British public health system, are subject to the quality and performance stan- dards and to the corresponding inspection systems and, therefore, their performance is constantly monitored by the Care Quality Commission and by Monitor who assures that each Hospital Foundation performs in compliance with the terms established in the work licence [26].

As from 2005 the system of payment by results was introduced in the NHS, characterized by payment to the different NHS organisations for the services rendered (prospective financing system [27]) according to a tariff table previously defined. In this manner, the financing of these organisations becomes dependent on their performance level and simultaneously a competitiveness factor is gradually introduced among the organisations to ensure the highest financing possible [28] - the latter depending on the satisfaction of the needs of the target population since in the event of incompliance with the contracted levels, the contractors may find alternative suppliers. It is also guaranteed that the users are provided with the healthcare required, as far as they are on the list of contracted care services contained in the work licence of a Foundation Trust, since the Foundation Trust is not recognised to alter the terms of this licence [29].

The establishment of the creation of NHS Foundation Trusts has played a key role in sustaining the progress the NHS has made in recent years. NHS Foundation Trust has promoted assessment in order to analyse the impact of this type of organisation on the progress and modernisation of the NHS. Namely, the studies carried out by the Healthcare Commission [30], Day and Klein [31], by a report by the King's Fund drew on Monitor's analysis to offer an King's Fund [32], all favourable to the creation of the Foundation Trusts. To bring the story up to date, by February 2008 there were 88 NHS Foundation. In June 2007, Ham and Hunt [33] promoted a review of the progress achieved in six NHS Foundation Trusts. The selection considered criteria such as the guarantee that different geographical areas of the country were covered, as well as a range of services and organisations that acquired the statute of NHS Foundation Trust in different moments. This report concluded that:

"In summary, our view, based on the evidence available to us, is that governance arrangements in Foundation Trusts are now established and are becoming increaseingly effective. More positively, there is untapped potential in the recruitment of 1 million members and more than 2000 governors in creating a quite different relationship between the NHS and the communities it serves. In this regard our findings accord more with the views of Lowe-Lauri [34] based on his experience at King's College NHS Foundation Trust, than the findings of the research undertaken by Lewis and Hinton [35] at the Homerton University Hospital NHS Foundation Trust in 2004/05. The difference between our findings and those 
of Lewis and Hinton may well be explained by the larger number of organisations included in our review and the more recent evidence we have been able to draw on."

To evaluate the State Hospital Foundations a SWOT Analysis [36] was performed. A strategic analysis was developed based on an external and an internal evaluation, but having as a reference the British experience described before. With this objective and in a first stage the State Hospital Foundation was characterised as a management model to identify the possibility of its implementation in Portuguese public hospitals. And, in a second stage, it was promoted an evaluation of the strategic capacity of this "new wave" to increase the main health economic objectives, and also see how it can be reflected in the process of empowerment and accounttability and in the regulatory system, taking into account the recent reform related with the introduction of the New Public Management.

\section{Results and Analysis}

The SWOT analysis is a strategic planning method aimed at evaluating the Strengths, Weaknesses, Opportunities and Threats underlying a particular project/strategy/objecttive. An analysis of this nature requires the specification of the objectives inherent to the project under study and the identification of the internal and external factors, both favourable and unfavourable to achieve the proposed goals [37].

The objective of the external analysis in a SWOT analysis is to identify the main Opportunities and Threats. That is, it is intended to identify which external influences may affect the project under study. Its importance lies in the need to foresee, whenever possible, future probable developments that may have a bigger or smaller impact on the same organisation or project. It involves the identification of the changes, which are out of the control of the organisation, but may produce repercussions (positive or negative) on its level of performance. On the other hand, the internal analysis intends to identify the main Strengths and Weaknesses that characterize a project, in a precise moment. It involves the evaluation of the strategic capacity inherent to the project and its competencies to adapt to changes. That is, it is intended to identify the internal factors.

The SWOT analysis is a flexible method and adaptable to the object in analysis, as it may be applied to evaluate both the competencies of an organisation and its external setting as well as to analyse the potentialities and internal and external constraints of a determined project. However, independently of what is intended to be evaluated, it should always combine, in an integrated manner, the elements of the internal and external analysis, to guaran- tee a trustworthy and reliable strategic diagnostic. In short, a SWOT analysis involves the following steps: identification of the followed strategy, or to follow, identification of the fundamental changes in the setting that influence the project under study, identification of the strengths and weaknesses of the project and crosscheck of the conclusions.

To accomplish this purpose its application becomes possible taking into account, on the one hand the theoretical framework presented, based on the evidence underlying the healthcare services, in a setting that recognises the right to healthcare access as a social right and, on the other hand, based on the empirical evidence of the constitution of Hospital Foundations in specific countries and its evaluation.

SWOT Analysis applied to the State Hospital Foundation:

1) Identification of the strategy to follow: Introduction of Hospital Foundations in the scope of the reform of the health sector.

2) Identification of the fundamental changes in the setting that influence the project under study - synthesis of the opportunities and threats:

\section{Opportunities}

a) The progressive increase of health expenditure and the need to obtain funds of a public or private nature which aim at guaranteeing universality of healthcare coverage;

b) Exhaustion of the traditional system: queries fundamental principles, such as equity, universality. Government failures;

c) Conflict between the traditional bureaucratic system and democracy promoting inefficiency;

d) Lack of structures and appropriate organisational processes in the public sector;

e) The constant growth of demand on the part of the citizens;

f) The lack of public accountability;

g) The New Public Management (NPM) in the public sector;

h) Profound changes in the modus operandi of Public Administration with reinforcement of the liberalisation and privatisation processes of the economic activities;

i) Public organisations centred on performance evaluation and result achievement;

j) Corporatisation in the public sector as a tool used in many western countries to control public expenditure and balanced budget;

k) Promotion dynamics, a new culture of corporate management based on the formal responsibilization of the different agents involved;

1) Decentralization of central power policies, empow- 
erment;

m)Promotion of the Participative State: Tendency to bring Public Administration closer to the citizens. The implementation of an "administration receptive to citizenship" promotes the required adaptation of public administration to the citizens' expectations (responsiveness);

n) Corporate governance became part of the public and private organisations;

o) Alteration of the hospital financing system: payment by results system to guarantee a more efficient application of the available resources.

II Threats

a) Permanence of the economic and financial crisis of the welfare state: The economic and financial insustainability of the state is still a reality and, therefore, the incapacity to satisfy many of the citizens', the community's and the health professionals' expectations, who continue to feel some dissatisfaction, may reach a level that may compromise the survival of the welfare state;

b) The possible "dis-intervention" and subsequent deresponsibilization of the state;

c) The possible recognition of the right to healthcare as a good of economic nature more than a social right;

d) The payment by results system may lead to "creamskimming" strategies, over-treatment situations, sacrificing quality in the healthcare services;

e) Lack of strong regulation and control from the state;

f) Arrangements for patient and public involvement in NHS Foundation Trusts may need to be reviewed to ensure that national policy in this area does not unintentionally hinder the development of governors and members.

3) Identification of the capacities and weaknesses of the project: synthesis of the strengths and weaknesses.

I Strengths

a) The foundation's responsibility is limited to the assets of the corporate entity;

b) A higher degree of management autonomy inherent to this model, a higher degree of freedom of access to capital, freedom to invest positive results in the development of new services for the local population, its matrix and participative structure may allow a better adjustment to the setting in which it operates;

c) Democratic model: the local population and staff elect directly their representatives. In this manner, it can be ensured that the state hospital foundation operates and is oriented in conformity with the needs of the community in which it is integrated; d) The model with emphasis on decentralization, empowerment and more control on the part of the society; by transfer of ownership and responsibility to the local community, may provide a more appropriate offer to the needs and expectations of the local population, in a more effective, efficient and just manner;

e) Greater responsibilization before the local population in which it is integrated, and before the regulator, reinforces not only the duty of accountability but also the community's active participation in decision-making on the options concerning healthcare services. This may promote a greater awareness in the consumption of healthcare. With the patient having more freedom of choice, there will also be an added concern regarding satisfaction, in an effort to achieve client loyalty. The tax-payer citizen may benefit from less waste of funds allocated to the health sector and more efficiency and investment to improve the conditions. The professionals may equally benefit from the added value and investment on continuous training and the development of incentives for productivity with the attribution of rewards;

f) The possibility of the stakeholders influencing the global management of the organisation and its strategic development may also increase the quality of services, as there will be added concern in adapting to the specific needs of the users and the community in which they are integrated;

g) In the scope of some of the international experiments, the legal and operational framework for this type of hospitals recognises a legal obligation of accountability both before its "members" and the public in general, through an independent regulatory entity that is directly responsible before Parliament;

h) Its performance is constantly accompanied and monitored through the evaluation of the quality of the services and efficiency in resource allocation;

II Weaknesses

a) Dependence on the financial transfers of the public sector may compromise the achievement of certain objectives of the State Foundation Hospitals;

b) Capture of the managing board by the public authorities;

c) Lack of representation of the stakeholders and, subsequently, its power in the hospital global management and its strategic development, may have negative implications on the legitimacy of decisionmaking leading to distortions;

d) The regulating authorities concentrating their activity on exclusively economic and financial evalua- 
tions;

e) NHS Foundation Trusts need to provide greater clarity on the role of the membership community and continue to develop the most effective ways of governors relating to members;

f) NHS Foundation Trusts need to consider a variety of approaches to ensure that governors and members relate effectively;

g) Governors need to be involved in the appraisal of the chair to ensure that any issues around the chair's role are identified and addressed before they become more significant;

h) Effective ways of engaging with members and reconnecting the NHS with the public.

\section{Conclusions}

The Hospital Foundation can be perceived as an alternative management model to the public hospitals. As well as the EPE hospitals, the Hospital Foundation model can promote some gains in terms of productivity and quality of care. Therefore, when comparing the two models a main difference can be observed. It is related with the governance model associated to the Hospital Foundation. Due to the management model (participative management), the process of accountability can be more "visible". As stated by Stephen Wilmot [38] "Foundation trusts will be more distanced from government than existing NHS bodies, and will have closer community links". Moreover, and also related with this type of management and with organisational structure of the hospital foundation, the regulatory process of this management model seems to be more effective.

However, we recognise that to confirm that this third "wave" can improve the hospital efficiency and the equity in healthcare delivery, empirical evaluations of hospitals must be developed. To conclude, the introduction of the Hospital Foundation model in the public hospitals - in Portugal as elsewhere - is a very plausible alternative as an attempt to solve the increasing costs of healthcare. However, the model of governance related with the Hospital Foundation can make the difference to promote its implementation.

\section{REFERENCES}

[1] G. Majone, "The Rise of the Regulatory State in Europe," West European Politics, Vol. 17, No. 3, 1994, pp. 77-101.

[2] G. Majone, "From the Positive to the Regulatory State: Causes and Consequences of Change in the Mode of Governance," Journal of Public Policies, Vol. 17, No. 2, 1997, pp. 139-167.

[3] P. Rosanvallon, "La Crisis del Estado Providencia," Madrid, Editorial Civitas, 1995.

[4] G. Boyne, C. Farrell, J. Law, et al., "Evaluating Public
Management Reforms: Principles and Practice," Managing the Public Services Series, Open University Press, Philadelphia, 2003.

[5] P. Noordhoek and R. Saner, "Beyond New Public Management: Answering the Claims of both Politics and Society," Public Organisation Review: A Global Journal, Vol. 5, No. 3, 2005, pp. 35-53.

[6] R. Meyer, "Changing Institutional Logics and Executive Identities: A Managerial Challenge to Public Administration in Austria," American Behavioral Scientist, Vol. 49, No. 7, 2006, pp. 1000-1014.

[7] O. Williamson, "Markets and Hierarchies," The Free Press, New York, 1975.

[8] K. Staley, "Voices, Values and Health: Involving the Public in Moral Decisions," King's Fund Publishing, London, 2001

[9] A. Sindane, "Public Administration Versus Public Management: Parallels, Divergences, Convergences and Who Benefits?" International Review of Administrative Sciences, Vol. 70, No. 4, 2004, pp. 665-672.

[10] A. Arndt and B. Bigelow, "Toward the Creation of an Institutional Logic for the Management of Hospitals: Efficiency in the Early Nineteen Hundreds," Medical Care Research and Review, Vol. 63, No. 3, 2006, pp. 369-394.

[11] OCDE, "Future Budget Pressures Arising from Spending on Health and Long-Term Care," Organisation for Economic Co-Operation and Development, Paris, 2006.

[12] D. Cutler and J. Horwitz, "Converting Hospitals from not-for-Profit to for-Profit Status: Why and What Effects?" In: D. Cutler, Ed., The Changing Hospital Industry. Comparing not-for-Profit and for-Profit Institutions, National Bureau of Economic Research, The University of Chicago Press, Chicago, 2000.

[13] D. Staiger and M. McClellan, "Comparing Hospital Quality at for-Profit and not-for-Profit Hospitals," In: D. Cutler, Ed., The Changing Hospital Industry. Comparing not-for-Profit and for-Profit Institutions, National Bureau of Economic Research, The University of Chicago Press, Chicago, 2000.

[14] A. Cadbury, "Corporate Governance and Chairmanship: A Personal View," Oxford University Press, Oxford, 2002.

[15] B. Coyle, "Corporate Governance," ICSA Professional Development 2003-4, ICSA Publishing Ltd, London, 2003.

[16] O. Hughes, "Public Management \& Administration: An Introduction," 2nd Edition, Palgrave, New York, 1998.

[17] J. Sussex, "The Economics of the Private Finance Initiative in the NHS," Office of Health Economics, London, 2001.

[18] G. Rego, R. Nunes and J. Costa, "The Challenge of Corporatisation: The Experience of Portuguese Public Hospitals," The European Journal of Health Economics, Vol. 1, No. 4, 2010, pp. 367-381. 
[19] G. Rego, C. Nunes, H. Melo and R. Nunes, "Distributive Justice and the Introduction of Generic Medicines," Health Care Analysis, Vol. 10, No. 2, 2002, pp. 221-229.

[20] M. Fahy, J. Roche and A. Weiner, "Beyond Governance. Creating Corporate Value through Performance, Conformance and Responsibility," John Wiley \& Sons Ltd., Chichester, 2005.

[21] R. Nunes, G. Rego and C. Brandão, "The Rise of Independent Regulation in Health Care," Health Care Analysis, Vol. 15, No. 3, 2007, pp. 169-177.

[22] R. Nunes, G. Rego and C. Brandão, "Healthcare Regulation as a Tool for Public Accountability," Medicine, Healthcare and Philosophy, Vol. 12, No. 3, 2009, pp. 257-264.

[23] P. Khaleghian and M. Gupta, "Public Management and the Essential Public Health Functions," World Development, Vol. 33, No. 7, 2005, pp. 1083-1099.

[24] GASB - Governmental Accounting Standards Board, "Concepts Statement No. 1. Objectives of Financial Reporting," GABS, Stanford, 1987, In: S. Ellwood and S. Newbury, Eds., "A Bridge too Far: A Common Conceptual Framework for Commercial and Public Benefits Entities," Accounting and Business Research, Vol. 36, No. 1, pp. 19-32.

[25] Monitor, Independent Regulator of NHS Foundation Trusts, NHS Foundation Trusts Model Core Constitution, London, September 2008.

[26] Monitor, Independent Regulator of NHS Foundation Trusts, Prudential Borrowing Code (PBC) for NHS Foundation Trusts, London, March 2005.

[27] R. Ellis and T. McGuire, "Hospital Response to Prospective Payment: Moral Hazard, Selection and Practice-Style Effects," Journal of Health Economics, Vol. 15, No. 6, 1996, pp. 257-277.
[28] D. Hodgkin and T. McGuire, "Payments Levels and Hospital Response to Prospective Payment," Journal of Health Economics, Vol. 13, No. 1, 1994, pp. 1-29.

[29] Department of Health, "A Short Guide to NHS Foundation Trusts," London, November 2005.

[30] Healthcare Commission, The Healthcare Commission's Review of NHS Foundation Trusts, Healthcare Commission, London, 2005.

[31] P. Day and R. Klein, "Governance of Foundation Trusts: Dilemmas of Diversity," The Nuffield Trust, London, 2005.

[32] R. Lewis, "Governing Foundation Trusts: A New Era for Public Accountability,” King's Fund, London, 2005.

[33] C. Ham and P. Hunt, "Membership Governance in NHS Foundation Trusts: A Review for the Department of Health," University of Birmingham, MUTUO, London, March 2008.

[34] M. Lowe-Lauri, "Foundation Trusts Governors can and should Exercise their Influence in the Wider Community to Benefit Services Users," Health Service Journal, Vol. 13, March 2008.

[35] R. Lewis and L. Hinton, "Citizen and Staff Involvement in Health Service Decision Making: Have National Health Service Foundation Trusts in England given Stakeholders a Louder Voice?" Journal of Health Services Research and Policy, Vol. 13, No. 1, 2008, pp. 19-25.

[36] C. Piggot, "Business Planning for Healthcare Management," 2nd Edition, Open University Press, London, 2000.

[37] G. Johnson and S. Kevan, "Exploring Corporate Strategy," Prentice Hall, Cambridge, 1996.

[38] S. Wilmot, "Foundation Trusts and the Problem of Legitimacy," Health Care Analysis, Vol. 12, No. 2, 2004, pp. 157-169. 